\title{
EFFECT OF OCCUPATIONAL HEALTH SAFETY PLANNING IN THE IMPLEMENTATION OF OCCUPATIONAL HEALTH AND SAFETY PROGRAMS IN STATE CORPORATIONS IN NAKURU TOWN, KENYA
}

\author{
James Gichuru Muiruri \\ School of Entreprenuership, Procurement \& Management \\ Jomo Kenyatta University of Agriculture and Technology, Kenya \\ Josphat W. Kwasira \\ School of Entreprenuership, Procurement \& Management \\ Jomo Kenyatta University of Agriculture and Technology, Kenya
}

\begin{abstract}
Occupational health and safety is a fundamental concept that continues to be associated with human resource issues. The importance of OHS programs is founded on the premise that the workforce requires care just like any other resources within an organization. Needless to say, State corporations are subject to health and safety issues. These firms presumptively face numerous challenges bordering on health and safety of their employees. Though, employees are expected to work in environments where their health and safety are assured, sometimes this is not the case. This justifies the essence of having sound OHS programs in place and ensures they are fully implemented. Generally, the study sought to examine the role played by the HR function in the implementation of $\mathrm{OHS}$ in the State corporations in Nakuru town, Kenya. In particular, the study investigated the influence of training on OHS programs, appraisal of OHS programs, audit of OHS programs, and planning of OHS programs on the implementation of OHS programs in State corporations. It was guided by four theories which included economic theory, theory of compensating wage differentials, Perrow's normal accident theory, and social judgment theory. This study adopted descriptive survey research design. The study targeted the 919 employees working with State corporations in Nakuru town. Stratified random sampling technique was used to draw sampled respondents from the target population. A structured questionnaire was employed to collect primary data. Both reliability and validity of the research instrument were determined prior to data collection for the main study. The collected primary data was processed and analyzed with the help of the Statistical Package for Social Sciences (SPSS) analytical tool. Data analysis was in form of both descriptive and inferential statistics. The study findings were presented in form of statistical tables. The study found out that the human resource function played a considerable role in the implementation of OHS programs in State corporations in Nakuru town. More specifically, the implementation of OHS programs in the said organizations was noted to be significantly and positively influenced by training on OHS programs, appraisal of OHS programs, audit of OHS programs, and planning of OHS programs. The study recommended that that training on health and safety issues should be emphasized; appraisal of these programs are upheld and conducted regularly; OHS audit should be regularly conducted by the internal human resource department; and corporations should involve all stakeholders and planning professionals in the planning of OHS matters.
\end{abstract}

Keywords: Human Resource Function, Occupational Health and Safety, Nakuru County.

\section{Council for Innovative Research}

Peer Review Research Publishing System

\section{Journal: International Journal Of Management \& Information Technology}

Vol. 10, No 9

editorsijmit@gmail.com

www.ijmit.com 


\subsection{INTRODUCTION \\ 1.1.1 Background of the Study}

Occupational health and safety abbreviated as OHS is a fundamental concept that continues to be associated with human resource issues. It is one of the most crucial yet controversial issues abound human resource management discipline. This assertion is supported by the keen interest of researchers in OHS issues (Rotich \& Kwasira, 2015).

\subsubsection{Human Resource Management Function}

According to Boyd (2003) the human resource is increasingly giving greater attention to OHS as it is not only a major component of the Human Resource function but it is increasingly associated with the achievement of operational efficiencies and competitive advantage in business organizations. However he notes that more concern needs to be addressed to the OHS to unravel OHS issues neglected by many researchers. The HRM function constitutes of a number of components which include planning, training, audit, and appraisal.

In the context of OHS programs, the HRM function plays a fundamental role. Employees should be trained on these programs in order for those programs to be implemented effectively. OHS programs embody such systems as the Occupational Health and Safety Management Systems (OHSMS). These are a set of interrelated or interacting elements to establish OHS policies and objectives and to achieve those objectives (ILO 2001). These systems as noted by Frank and Waren (2000) constitute voluntary and mandatory OHSMS. OHSMS are aimed at improving planning, implementation, evaluation and continual improvement directed towards abatement of hazards in the workplace, (Institute for Work and Health Report, 2005).

\subsubsection{Occupational Health and Safety Programs}

The importance of OHS programs is founded on the premise that the workforce requires care just like any other resources within an organization. Indeed, a safe workplace enhances employee satisfaction (Kreitner, 2007). The scholar held the opinion that employee satisfaction is subject to a number of factors. These include working in an environment that assures them of physical, psychological and emotional wellness. Though, the OHS issues are firmly enshrined in law, Dessler (2008) reasons that an organization genuinely concerned with the health and safety of its workforce ought to go beyond the scope of legal stipulations in address OHS programs.

Ng'eno and Muathe (2014) when citing the American Council on Exercise (2000) concurred that when a firm creates leisure time in the due course of a working day enables employees to recharge themselves mentally, psychologically and emotionally. This leads to improved performance at the workplace. It is acknowledged that both private and public entities all over the world have continued with inculcating leisure activities and wellness programs in their work routine with the aim of promoting mental and physical health of their employees. It is further noted that many firms continue investing in large sums of money to provide recreational amenities within the workplace. This has also reduced the cases of absenteeism and also raised both employee and organizational performance (Taylor, 2008).

Moreover, Aditya, Puplampu, Kwesi and Andreou (2012) delved into the theme of occupational safety and health (OHS) and corporate social responsibility (CSR) in Africa. They admitted that occupational injury and illness are matters of health in as much as they are matters of economics. The argument is based on the assertion that both injury and illness emanate from work and the latter is an economic activity. According to the authors, OHS encompasses both causes and consequences of occupational injuries and illness.

In other words, OHS examines the role played by economic factors regarding the genesis of ill-health at the workplace; and also addresses the effects the foregoing has on the economic prospects for the workforce, organization, nation and the world at large. According to Aditya et al (2012), occupational injuries and ill-health are more common in developing than in developed countries. This has occasioned many intensified social problems in these countries; a situation that has exacerbated hardship, insecurity and anxiety across the world.

It is asserted that in Kenya, the theme of occupational health and safety is addressed in the Workman's Compensation Act 2007. The Act stipulates the requirements of the employer in ensuring that the workers operate in safe and conducive working environment. The environment should be free of injuries; physical and/or otherwise (Makori, Nandi, Thuo\&Wanyonyi, 2012). However, statistics indicate that employers still resisting OHS programs basing their refusal on increased labour costs claims. Employees working in industrial organizations and factories are the most susceptible to injuries and even death in the line of duty.

Resultantly, the law demands that such firms must have OHS programs in place. In Kenya, factories and industries are required to be registered with the Department of Occupational Health and Safety (Nyakang'o, 2004). The author further reveals that by the close of 2004, about 11,000 such firms were registered. The aforestated figures effectively exclude both micro and small enterprises (MSEs). In Kenya, reports indicate that the mining, construction, transport and other sectors where tools and machinery are employed are highly prone to OHS issues. In 2003, statistics indicated that mining, construction and transport sectors recorded the highest compensation claims from employees at 41 per cent.

The firms where there are machines to be either operated or assembled recorded 28 per cent compensation claims. All other sectors recorded just 31 per cent of workplace accidents (Makori et al., 2012). Wazir (2013) examined the challenges affecting the implementation of health and safety programs in Kenya airways, which is one of the leading State corporations in Kenya. The author observed that, in spite of the school of thought that advocates for individual employees to ensure that they are safe at the workplace; the employing organization is duty-bound to prevent accidents and at the 
same time address health and safety hazards. This, it is noted, would result in reduction of loss emanating from accidents and injuries at the workplace.

\subsubsection{State Corporations}

State corporations otherwise referred to as parastatals are established under State Corporations Act, Chapter 446 of the Laws of Kenya. Each of these corporations is headed by a board of directors, chief executive officer and an advisory committee. The State corporations are established by the order of the President. These entities are mandated to carry out specific functions stipulated by the Act. Corporations fall under various categories which include public universities, public tertiary colleges, and parastatals, amongst others.

\subsubsection{Nakuru Town}

Nakuru town is the headquarters for Nakuru County and the former Rift Valley Province. It is the fourth largest town in Kenya after the cities of Nairobi, Mombasa and Kisumu. It is a cosmopolitan town located on the floor of the Great Rift Valley. In Nakuru town, there are a couple of State corporations whose representation is in form of branches. These include the Geothermal Development Company (GDC), Kenya Pipeline Ltd, Kenya Power, Agricultural Finance Corporation (AFC), Kenya Railways, National Bank of Kenya, Jomo Kenyatta University of Agriculture and Technology, Egerton University, Kenyatta University, University of Nairobi, Kenya Industrial Training Institute (KITI), Pyrethrum Board of Kenya, Kenya Bureau of Standards, Kenya Bureau of Statistics, Kenya Revenue Authority, and Postal Corporation of Kenya.

\subsection{Statement of the Problem}

TheStatecorporations face numerous challenges bordering on health and safety of their employees. The employees' health in this context is both physical, psychological. On the other hand, the safety of the employees is subject to the environment at the workstation. When handling tools, equipment and machines, employees are vulnerable to injuries and even death. Though, employees are expected to work in environments where their health and safety are assured, sometimes this is not the case. Pressure at work contributes to psychological ill-health of the employees which is likely to negate their performance and productivity. Poor and unsafe workstations are likely to result injuries and sometimes death. In year 2014, for instance, according to the department of Health Engineering at the Kenya Power firm in Nakuru town 13 injury cases were reported while the Geothermal Development Company (GDC) had 16 casualties in the same year according to the statistics of their HR department. The organization concerned is likely to suffer immensely in the event the foregoing circumstances are witnessed. For instance, injuries are likely to result in absenteeism through sick leaves while death will reduce the size of the workforce and organizational productivity. The organizations are also likely to be sued for compensation by the affected employees and/or their next of kin, the latter in case death occurs. Therefore, it is very necessary to have sound OHS programs in place and ensure they are fully implemented.

\subsection{Purpose and Objective of the Study}

The purpose of this study was to analyze the effect of OHS planning on implementation of OHS programs.

\subsection{Research Hypotheses}

$\mathbf{H}_{01}$ : There exists no significant relationship between OHS planning and implementation of OHS programs

\subsection{LITERATURE REVIEW 2.2 Theoretical Framework}

The study reviews theories that touch on occupational health and safety. The theories include economic theory, theory of compensating wage differentials, Perrow's normal accident theory, and social judgment theory.

\subsubsection{Economic Theory}

The economic theory states that employers usually determine whether to prevent workplace accidents or illnesses by making a comparison between the cost of prevention of the accidents and hazards and the cost of not taking such actions. The theory further maintains that employers who fail to reduce hazards associated with the workplace expect to pay increased labor costs because workers will demand additional compensation for enduring occupational safety and health risks. Workers will demand a wage premium; this implies that when workers are fully aware of the job risks, they will seek compensation equal to the expected cost of injury or illness not covered by workers wage. In addition, the theory identifies that employers may have to pay for the costs of recruitment and training of new or additional workers to replace those workers who are injured or killed in the due course of work.

In order to avoid unplanned expenses, the theory states that employers will invest in safety and health improvements and programs until the cost of additional precautions is more than paying wage premiums and other related costs. In line with the theory, firms should incorporate OHS programs and plans in their objectives so as to mitigate and abate some of safety and health hazards. Workers should then be compensated for risks that remain if the organization cannot abate all the risks. The benefits attributed to this are obvious, employers' product and service will be more efficient since the price of the product or service will include the cost of occupational illnesses and injuries associated with production. In this manner the price will reflect the cost to the society of the production of goods and services. However, the actual cost of paying compensation will depend on the nature of its insurance arrangements. 


\subsection{Conceptual Review}

The study reviews the various studies that have been carried out globally, regionally and locally relative to occupational health and safety programs and their implementation.

\subsubsection{Occupational Health and Safety Planning}

Planning is a process for results-oriented decision making. Modern safety management requires excellent planning to ensure wise stewardship of limited resources, solid credibility with senior managers, and demonstrable success in achieving rational corporate OHS goals (Don \& Associates Itd Fredericton, 2011). It is further stated that good managers must plan for stability, adaptability and contingency. Corporations have strategic, long term plans, operational and single use plans that are the roadmap to achieving corporations' goals and objectives. In relation to OHS, Safety professionals are engaged in these plans at various levels because of the scope and breadth of safety management systems in the corporate setting.

A paper prepared by Glorian and Elizabeth (2004) on Integrating Occupational Health and Safety and Worksite Health Promotion at Harvard School of Public Health states that OHS programs or interventions aimed at improving workers health and safety should be carefully planned, be the OHS specific or Worksite Health Promotion. Carefully planned OHS programs help to evaluate the impact of these programs to prevent work-related injuries and illnesses that derail the achievement of economic objectives. In addition, the NOHSAC National Occupational Health and Safety Advisory Committee (NOHSAC, 2009) technical report on OHS in small businesses in New Zealand states that business firms should have active involvement of different partners in the planning and implementation of this OHS programs as management own decisions and implementation of OHS programs have failed. Government agencies and corporations need to take into account the changing nature of work, in planning and delivering services to small businesses. This is to ensure informed planning and assessment of laid down plans in regards to health and safety in this corporations and businesses. Vulnerable workers such as casual labourers, older workers, new migrants, and people with low literacy require special attention and protection in terms of their health.

From the analysis of Gallagher's study (2000) of the relationship between OHSMS type and system performance based on the case study evidence collected in 1990s from twenty organizations that had implemented OHSMS in Australia, it asserts that the type of OHSMS may influence OHSMS success of failure. The adaptive hazard managers stand out from the unsafe minimizing act by performing better on hazard elimination. This is attributed from the well planned approach to hazard management for the all spectrum of hazards as opposed to other cases where system activity appeared to be aimed at improving the OHSMS. Gallaghers' findings portray the critical role of senior managers and of employee involvement in consultation particularly on planning matters of the $\mathrm{OHS}$.

Further, the study suggests that safety representatives should embrace more mainstream health and safety management planning, implementation and review rather than concentrating on the margins of safety and health management.A study on occupational health and safety management in the Norwegian Oil and Gas Industry by Jan, Terje and Bodil (2008) suggests that good understanding among employers and employees is crucial in planning and making good decision on occupational Safety and Health Management. Lack of cooperation between the two parties posed a big problem to safety and Health management programs. It is therefore noted that collective responsibility is of utmost importance to ensure successful planning and implementation of OHS program.

It is stated that OHS and corporate social responsibility (CSR) in Africa according to Worlds Health Assembly endorsed a global plan of action on workers health for the period 2008 to 2017 (Aditya et al., 2012). The plan embraced by 193 World Health Organization (WHO) member states saw the need for globally coherent framework for planning, delivery and evaluation of essential interventions for workplace health protection and promotion. The results from the workshop carried out in 2009 comprising 56 experts from 22 countries shows that the model brings together all aspects related to the workers health and highlights the key drivers of enterprises for developing healthy workplaces and promoting workers' health (Jain, 2012).

\subsubsection{Occupational Safety and Health Act}

The Occupational Safety and Health (OHS) Act 2007 falls under Chapter 424 of the Kenya's Constitution. The Act addresses the employee safety training, equipment or mechanical safety, noise levels, personnel, personal protective equipment, safety records, first aids, amongst other safety issues. These aspects are addressed under various sections of the Act. The Act provides for the safety, health and welfare of workers and all persons lawfully present at workplace. It further provides for the establishment of the National Council for Occupational Safety and Health and for connected purposes.

The OHS Act applies to all workplaces where any person is at work, whether temporarily or permanently. The Act is purposed to secure the safety, health and welfare of persons at work, and protect persons other than persons at work against risks to safety and health arising out of, or in connection with, the activities of persons at work. The Act further provides that every employer should ensure the safety, health and welfare at work of all persons working in his workplace.

Every occupier shall carry out appropriate riskassessments in relation to the safety and health of personsemployed and, on the basis of these results, adopt preventiveand protective measures to ensure that under all conditions oftheir intended use, all chemicals, machinery, equipment, toolsand process under the control of the occupier are safe andwithout risk to health and comply with the requirements ofsafety and health provisions in this Act.Every occupier shall take immediate steps to stop anyoperation or activity where there is an imminent and seriousdanger to safety and health and to evacuate 
all personsemployed as appropriate (Republic of Kenya, 2007). It is, needless to say, that all State corporations regardless of their functions are expected to abide to the health and safety regulations laid down by the OHS Act, 2007.

\subsubsection{Implementation of OHS Programs}

A survey by the International Labour Organization (ILO, 2001) and a study by Frank and Warren indicated that OHS programs embody such systems as the Occupational Health and Safety Management Systems (OHSMS). OHSMS are aimed at among others, implementation of health and safety programs geared to minimizing hazards in the workplace. A technical report on OHS in small businesses in New Zealand states that business firms should have active involvement of different partners in the planning and implementation of this OHS programs as management own decisions and implementation of OHS programs have failed (NOHSAC, 2009).

More so, Gallagher (2000) examined the relationship between OHSMS type and system performance based on the case study from twenty organizations that had implemented OHSMS in Australia. The author noted that the type of OHSMS may influence OHSMS success of failure. The study also indicated that safety representatives should embrace more mainstream health and safety management planning, implementation and review rather than concentrating on the margins of safety and health management. another study conducted in Norway noted that collective responsibility is of utmost importance to ensure successful planning and implementation of OHS program (Jan et al., 2008).

In Kenya, Wazir (2013) examined the challenges affecting the implementation of health and safety programs in Kenya airways, which is one of the leading State corporations in Kenya. The study observed that in spite of the school of thought that advocates for individual employees to ensure that they are safe at the workplace; the employing organization is dutybound to prevent accidents and at the same time address health and safety hazards. The foregoing measures are likely to reduce losses occasioned by accidents and injuries at the workplace.

\subsection{Conceptual Framework}

A conceptual framework outlines the perceived relationship between the study variables as shown in Figure 1.

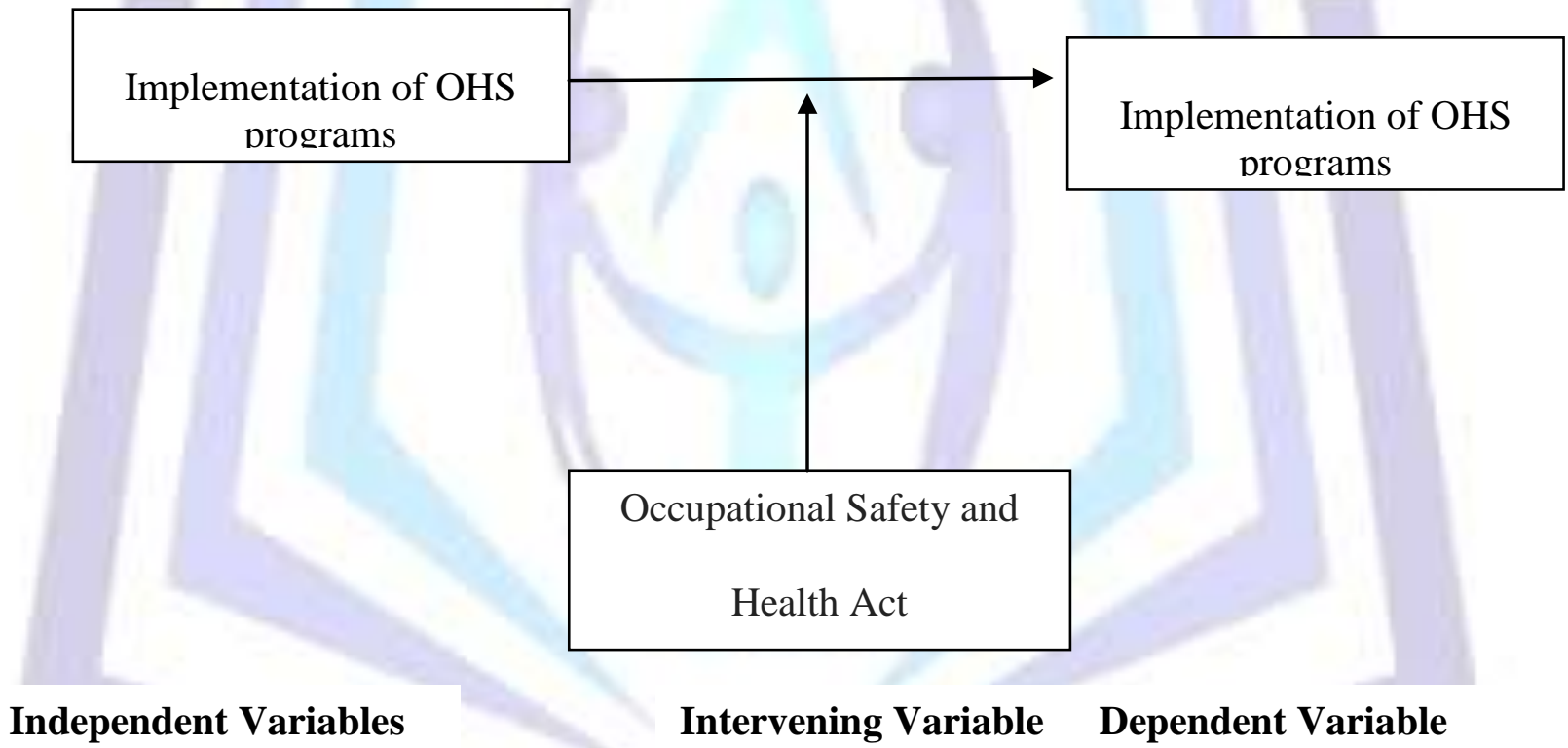

Figure 1: Conceptual Framework

\subsection{Summary of the Reviewed Literature}

Planning is a process for results-oriented decision making. Modern safety management requires excellent planning to ensure wise stewardship of limited resources, solid credibility with senior managers, and demonstrable success in achieving rational corporate OHS goals. Corporations have strategic, long term plans, operational and single use plans that are the roadmap to achieving corporations' goals and objectives. It is stated that business firms should have active involvement of different partners in the planning and implementation of the OHS programs because management own decisions and implementation of OHS programs have failed. 


\subsection{RESEARCH METHODOLOGY \\ 3.1 Research Design}

This study adopted descriptive survey research design. Descriptive studies provide precise and valid representation of the variables relevant to the research questions. On the other hand, survey studies, unlike longitudinal studies are conducted at a given point in time. These justified the choice of descriptive survey research design for the present study.

\subsection{Sampling Frame}

Kothari (2004) asserted that a sampling frame is an exhaustive list of individuals from whom the sample will be derived. Therefore, the sampling frame for this study constituted of all the 919 employees across the 17 State corporations with establishments in Nakuru town.

Table 1: Sampling Frame

\begin{tabular}{|c|c|c|}
\hline \multicolumn{2}{|c|}{ State Corporations } & Number of Employees \\
\hline i. & Kenya National Highway Authority - South Rift & 29 \\
\hline ii. & Kenya Bureau of Standards & 18 \\
\hline iii. & National Social and Security Fund & 42 \\
\hline iv. & Rift Valley Water and Services Board & 35 \\
\hline v. & Betting Control and Licensing Board & 17 \\
\hline vi. & National Hospital Insurance Fund & 24 \\
\hline vii. & Kenya Railways Authority & 9 \\
\hline viii. & Kenya Power & 207 \\
\hline ix. & Kenya Revenue Authority & 53 \\
\hline$x$. & Kenya Postal Corporation & 153 \\
\hline xi. & Pyrethrum Board of Kenya & 47 \\
\hline xii. & Kenya Dairy Board & 16 \\
\hline xiii. & Kenya Pipeline Corporation & 143 \\
\hline xiv. & Kenya Cooperative Creameries & 28 \\
\hline $\mathrm{xv}$. & Kenya Rural Roads Authority & 32 \\
\hline xvi. & Kenya Urban Roads Authority & 15 \\
\hline xvii. & National Cereals and Produce Board & 51 \\
\hline tal & & 919 \\
\hline
\end{tabular}

\subsection{Sample Size}

A valid sample according to Kitchenham and Pfleeger (2002) is a representative subset of the target population. Nassiuma's (2009) formula was used to calculate the sample size as illustrated hereafter.

$$
\begin{aligned}
n=\frac{N C^{2}}{C^{2}+(N-1) e^{2}} & \text { Where } \\
& \mathrm{n}=\text { sample size } \\
& \mathrm{N}=\text { target population size } \\
& \mathrm{C}=\text { coefficient of variation }(0.5) \\
& e=\text { margin of error }(0.05)
\end{aligned}
$$

Interpretatively:

$$
\begin{aligned}
& \mathrm{n}=\frac{919 \times 0.5^{2}}{0.5^{2}+(919-1) 0.05^{2}} \\
& \mathrm{n}=90.28 \\
& \mathrm{n}=91 \text { employees }
\end{aligned}
$$

This implies that the sample size was 91 employees of State corporations in Nakuru town. 


\subsection{Sampling Technique}

The study adopted stratified random sampling technique to draw the sampled employees from the State corporations in Nakuru town. Stratified random sampling method was occasioned by the fact that the various State corporations (strata) in the aforesaid town had different numbers of employees. Therefore, to minimize sampling bias, the sampled respondents were distributed across the 13 State corporations subject to their sizes.

\subsection{Data Collection Procedure}

Upon the validation of the research instrument, the next phase was collection of data from the sampled respondents. The first step was seeking the requisite permits from the Jomo Kenyatta University of Agriculture and Technology - Nakuru CBD Campus, and the management of State corporations from where the respondents had been drawn. The structured questionnaire was then administered through the HR department or the organization's administration/management. The sets of the filled questionnaire were then collected through the same channel.

\subsection{Data Processing and Analysis}

The collected primary data were processed and analyzed with the help of the Statistical Package for Social Sciences (SPSS) analytical tool. Data analysis was in form of both descriptive and inferential statistics. Descriptive statistics captured the frequencies, percentages, means, and standard deviations. On the other hand, inferential statistics constituted the Pearson's correlation coefficient and enabled the determination of the relationship between each of the independent variables (training on OHS programs, appraisal of OHS programs, audit of OHS programs, and planning of OHS programs) and the dependent variable, that is, implementation of OHS programs. The study findings were presented in form of statistical tables.

\subsection{Results and Findings}

The researcher administered questionnaires on a total of 91 sampled respondents across the 13 State Corporations in Nakuru town. 78 questionnaires which had properly been filled were returned. This was equivalent to 85.71 per cent return rate or response rate.

\subsection{Descriptive Findings}

In this section, the views of the respondents are presented relative to training on health and safety issues, appraisal of occupational health and safety programs, occupation health and safety audit, occupational health and safety planning, and implementation of occupational health and safety planning. The findings are presented in form of measures of central tendency (mean) and measures of variation (standard deviation).

\subsubsection{Occupational Health and Safety Planning}

The study further analyzed the views of the participants in respect to occupational health and safety planning. Table 3 indicates the respondents' views in respect to this subject.

Table 3: Descriptive Statistics for OHS Planning

\begin{tabular}{|c|c|c|c|c|c|c|}
\hline & & $\mathbf{N}$ & Min & Max & Mean & $\begin{array}{l}\text { Std. } \\
\text { Dev }\end{array}$ \\
\hline i. & Planning is vital in decision making & 78 & 1 & 5 & 4.50 & .849 \\
\hline ii. & Carefully planned OHS programs prevent work-related injuries and illnesses & 78 & 1 & 5 & 4.27 & .907 \\
\hline iii. & All stakeholders are involved in OHS programs' planning & 78 & 1 & 5 & 3.76 & 1.083 \\
\hline iv. & Our corporation undertakes occupational health and safety planning & 78 & 1 & 5 & 4.05 & .992 \\
\hline v. & $\begin{array}{l}\text { The scope and breadth of safety management systems is wide in our } \\
\text { corporation }\end{array}$ & 78 & 1 & 5 & 3.90 & 1.123 \\
\hline vi. & $\begin{array}{l}\text { Our corporation engages safety professional in OHS planning due to the } \\
\text { wide scope and breadth of safety management systems }\end{array}$ & 78 & 1 & 5 & 3.85 & .968 \\
\hline vii. & OHS planning improves employees' health and safety & 78 & 1 & 5 & 4.21 & 1.011 \\
\hline
\end{tabular}

The study findings revealed that respondents strongly concurred (mean $=4.50$; stddev $=0.849$ ) that planning was vital in decision making In addition, respondents admitted that carefully planned OHS programs prevented work-related injuries and illnesses;all stakeholders were involved in OHS programs' planning;their corporation undertook occupational health and safety planning;the scope and breadth of safety management systems was wide in their corporation;their corporation engaged safety professional in OHS planning due to the wide scope and breadth of safety management systems and that OHS planning improved employees' health and safety. The relatively small standard deviation across most of the propositions implied that respondents held close opinions regarding the same statements. 


\subsubsection{Role of OHS Planning in Implementation of OHS Programs}

The relationship between the two constructs was investigated and the results are presented in Table 4 below.

Table 4: Relationship between OHS Planning and Implementation of OHS Programs

Implementationof OHS programs

\begin{tabular}{llr}
\hline OHS Planning & Pearson Correlation & $.755^{* \pi}$ \\
& Sig. (2-tailed) & .000 \\
$\mathrm{n}$ & 78 \\
\hline$* *$ Correlation is significant at the 0.01 level (2-tailed).
\end{tabular}

\footnotetext{
**. Correlation is significant at the 0.01 level (2-tailed).
}

It was found that the relationship between OHS planning and implementation of OHS programs was strong, positive and statistically significant $(r=0.755 ; p<0.01)$. The fourth null hypothesis was thus rejected. This meant that OHS planning positively influenced the implementation of OHS programs. In other words, planning properly and adequately for implementation of $\mathrm{OHS}$ ensured that the programs implementation was a success. The enhancement of implementation was as a result of involving stakeholders including professional in the planning process. Therefore, it was deduced that careful and adequate OHS planning was of utmost essence in the implementation of OHS programs. The study findings were in agreement with Jan, Terje and Bodil's (2008) findings where they rationalized the importance of planning making good decision on occupational safety and health management.

\subsection{Summary of the Findings}

This section outlines a summary of the major study findings in tandem with the study objective. The summary highlights the findings of descriptive and inferential analysis for the theme under study.

\subsubsection{OHS planning and Implementation of OHS programs}

It was absolutely agreed that planning was vital in decision making. Moreover, they were in agreement that carefully planned OHS programs prevented work-related injuries and illnesses;all stakeholders were involved in OHS programs' planning;their corporation undertook occupational health and safety planning;the scope and breadth of safety management systems was wide in their corporation;their corporation engaged safety professional in OHS planning due to the wide scope and breadth of safety management systems and that OHS planning improved employees' health and safety. Further analysis indicated that the relationship between OHS planning and implementation of OHS programs had a strong, positive and statistically significant $(r=0.755 ; p<0.01)$.

\subsubsection{Implementation of OHS programs}

The respondents admitted that their corporation had OHS programs and that all employees including the management team were involved in implementation of OHS program. In addition,it was agreed that training employees on OHS programs enhanced the programs' implementation;appraisal of OHS programs facilitated programs' implementation;effective implementation of OHS programs was subject to effectiveness of OHS audit and that OHS planning played an important role in the implementation of OHS programs in our corporation.

\subsection{Conclusions.}

The study made a number of inferences in respect to the role of human resource function in implementation of occupational health and safety programs. This inference was made relative to the study construct which was safety planning and implementation of occupational health and safety programs.

\subsubsection{Effect of OHS planning on Implementation of OHS programs}

It was concluded that planning was vital in decision making and that all stakeholders were involved in OHS programs' planning in the corporation. In addition it was noted that theircorporationengaged safety professional in OHS planning due the scope and breadth of safety management systems. It was further inferred that carefully planned OHS programs improved employees' health and safety by preventing work-related injuries and illnesses. OHS planning was therefore concluded critical in the implementation of OHS programs.

\subsection{Recommendations}

This part outlines the recommendations made resulting from the study findings. The recommendations are made in line with the objectives and findings.

\subsubsection{Recommendation on Occupational health and Safety Planning}

The study recommends that corporations should involve all stakeholders and planning professionals in the planning of OHS matters. This is to ensure that all the stakeholders including management support the implementation of such programs. 


\subsection{Recommendation for Further Research.}

The study suggests areas to be further investigated in regard to the human resource function in implementation of OHS programs in Kenya.Scholars and researchers are encouraged to study on "The effect of occupational health and safety audit on the implementation of occupational health and safety programs in petroleum companies", "Assessment of challenges affecting implementation of OHS programs in manufacturing firms", and "An assessment of the effectiveness of OHS management systems in mining companies".

\section{REFERENCES}

1) Aditya, K.J., Buenar, B.P., Kwesi, A.T., \& Nicholas, J.A.A. (2012). Occupational safety and health and corporate social responsibility in Africa: Repositioning corporate social responsibility towards national development. Bedfordshire,United Kingdom:Cranfield Press.

2) Boyd, C. (2003). Human Resource Management and Occupational Health and Safety.

a. London: Routledge.

3) Dessler, G. (2008), Human Resource Management (1 $1^{\text {th }}$ Ed.). New Delhi: Prentice-Hall of India Private Ltd.

4) Franken, J. R., \&Wallen N. E. (2000). How to Design and Evaluate Research in Education. London: McGraw Hill.

5) Gallagher, C. (2000). Occupational Health \& Safety Management Systems: System Types and Effectiveness, Unpublished PhD thesis, Deakin University, Melbourne.

6) International Labour Organization(2000). Paper presented at the International Labour Conference 8th session agenda, Geneva, Switzerland.

7) Jain .I, Puplampu, B.B., Amponsah-Tawiah, K. \&. Andreou, N.J.A. (2012). Occupational Safety \& Health and Corporate Social Responsibility in Africa: Repositioning Corporate Social Responsibility towards National Development.

8) Jan, H., Terje, L., Jan, E.K. \&Bodil, A. (2008). A study of occupational health and safety management in the Norwegian oil and gas industry. Safety Science 46: 493- 509.Journal of construction engineering and management (C) ASCE / July2008 / 817

9) Kreitner, R. (2007). Management (10 ${ }^{\text {th }}$ Ed.). Boston: Houghton Mifflin Company.

10) Makori, E. M., Nandi, O. M. J., Thuo, J. K., \&Wanyonyi, K. W. (2012). Influence of $\quad$ occupational health and safety programmers on performance of manufacturing firms in Western Province, Kenya. African Journal of Historyand Culture (AJHC), 4(4), 46-58.

11) Ng'eno,W.K.,\&Muathe,S.M.A. (2014).Critical review of literature on employee wellness programs in Kenya, International Journal of Research in Social Sciences.

12) Nyakang'o, J. B. (2005). Status of occupational health and safety in Kenya. Paper $\quad$ presented at the Workshop on the IUPAC-UNESCO-UNIDO Safety Training Program,Beijing, China.

13) OHSA (2007). European Agency for Safety and Health at Work, Expert forecast on emerging psychosocial risks related tooccupational safety and health, Luxembourg: Office for Official Publications of the European Communities.

14) Rotich, L.C., \&Kwasira, J. (2015). Assessment of success factors in the implementation of occupational health and safety programs in tea firms in Kenya: A case of Kaisugu Tea Factory. International Journal of Economics, Commerce and Management, 3(5), 797-812. .

15) Republic of Kenya (2007). The Occupational Safety and Health Act, 2007. Nairobi: Government Printer.

16) Wazir, A.W. (2013). Challenges of implementing health and safety programmes in Kenya Airways (KQ). 